\title{
Only the Envelope: An Artistic Exercise in Data Retention
}

\section{Cover Page Footnote}

My acknowledgements are due to research assistant and performer Rachelle Rechichi; technology consultant Neil Ferguson; to all partici $\neg$ pants, consenting and otherwise; to eResearch Coordinator Heather Boyd, who reached out to me as a creative arts researcher; to Edith Cowan University's eResearch Technology Funding Scheme, and School of Arts and Humanities, for their financial support. 
Only the Envelope combines research methodologies to investigate the ways we share personal information in the public sphere, and document our practices as scholartists. I will begin with a brief description of the work and its contexts before moving to its status as performance research, touching on some of the methodological and ethical implications that arise. Discussion of the research project is grounded in interpretations of the research data, some of which take the form of documents such as photographs and videos. There is considerable overlap between the "work," the "research project," and the "documentation," where the relationships between these components are complex and reflexive. By installing a laboratory space in an artistic space, the work Only the Envelope takes the form of a research project; at the same time, the research project Only the Envelope: An Artistic Exercise in Data Retention ${ }^{1}$ depends upon the work to produce documentary data. Some of the documentation of the work can be said to represent the work, yet due to the ways in which the live artwork evolved, some documentation is indistinguishable from the work itself.

This complexity is a reflection both of the emergent nature of a process-driven creative arts research enquiry, and of the work's theme, which is digital surveillance and sharing personal information in the public sphere. Further, the complex relationships between work, project and documentation offer a way to engage with the traditional debate in performance studies about the supposed ephemerality of performance by illustrating Rebecca Schneider's position that, with reenactment art, "the live is a vehicle for recurrence" such that a distinction between record and performance collapses, and that photography can "mix theatricality and documentality." In Only the Envelope, the work refused to keep still to submit to its documentation, just as personal data in the public sphere is endlessly generated, captured, and recycled in unstable recursion.

\section{PART 1: THE WORK}

I will begin by introducing "the persons of the play" to clarify the discussion to follow. The author of this paper is also the artist responsible for the work, Only the Envelope (subsequently in this paper, OTE). I employed an assistant, Rachelle Rechichi, to play the role of the "scientist" Svetlana, who offered a single-character performance to each visitor to the installation work, visitors who usually arrived singly or in pairs. In playing her role, the "scientist" also captured various forms of 
data on each visitor. Once the work was underway--but before the work was archived-the artist stepped into the role of a visitor who engaged with Svetlana, and this interaction was captured on a head-mounted eye-tracking camera worn by the artist. This video re-enacts the visitor experience and extends the work's artistic outcomes, but is it "the work" or merely a "record" of the work? This can be considered the key research question explored here: How does performance praxis interact with performance documentation such that one does not supplant the other?

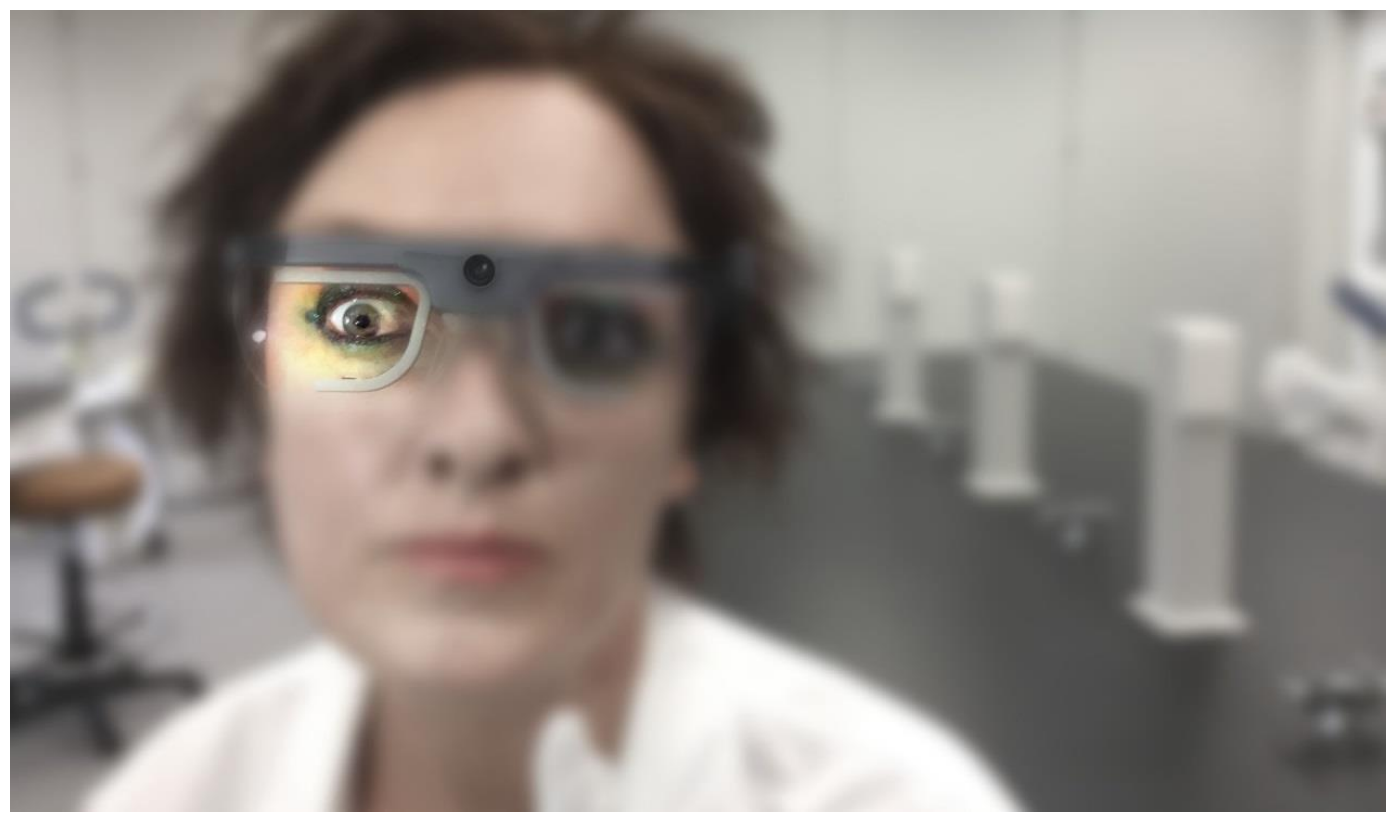

Rachelle Rechichi as the "scientist" Svetlana, Only the Envelope publicity image. Photograph by Vahri McKenzie.

The performance stage of the project was a work of live $\operatorname{art}^{3}$ in which a "scientist," both performer and research assistant, offered visitors the opportunity to be involved in an "experiment," by viewing an original video ${ }^{4}$ while wearing Tobii Pro Glasses 2, a wireless eye-tracking device. OTE appeared in a gallery space in which the performer, as laboratory technician, explicitly gathered demographic information and captured data about viewing behaviour of those visitors who agreed to "participate" by donating their personal data as they watched the video. Sometimes other visitors accompanied the "participant" and did not agree to share their personal data, but nonetheless can be considered to have participated in ways not initially anticipated. This distinction is interesting, in part because it raises an ethical dilemma around informed consent, as well as issues arising in process-driven creative arts research enquiries, and will be addressed in the "Research Project" section below. 
This project was instigated by my sense of complicity in large-scale data gathering, another expression of the troubling slippage between the authentic and the record. The role of science, its ability to appear neutral and objective, motivated the work's recursively playful performance of faith in technology embodied in the "scientist" with her powerful eye-tracking device, which juxtaposed the private experience of viewing art with the public experience of being under surveillance. In response to the polite-but-invasive requests of the "scientist", I had hoped to invite resistance or reflective decision making in visitors, as a way of exploring their own feelings on the matter of data retention. There was little evidence of this amongst those who gave their consent to participate in the work, though a greater freedom of response was observed amongst those who implicitly participated by observing the work or refusing to be involved. These findings are addressed elsewhere. ${ }^{5}$

The work's title, Only the Envelope, is a reference to the public debate that played out for a short time in Australia regarding the passing of the Data Retention Act. The Australian Government's Telecommunications (Interception and Access) Amendment (Data Retention) Act 2015 requires telecommunications companies to retain and secure certain records for a period of two years. Then-Prime Minister Tony Abbott memorably defended this new depth of data surveillance by using the analogue-era metaphor of the personal letter; the material to be gathered is the metadata, akin to the material on the front of the envelope, while the contents of the letter remain private. ${ }^{6}$ We need not worry about invasions of privacy, the metaphor implies, because it is only the envelope that is gathered. In the television interview in which the proposed legislation was first explained, Abbott made an error, later clarified, by referring to web-browsing history as metadata when it is in fact content. ${ }^{7}$ Abbott's confusion is indicative of the limited understanding the public has about large-scale data gathering, so-called "big data," with which we are now all complicit.

\section{Contexts}

One of several contexts that illuminate the present discussion is the relationship between performance, live art and installation. All three terms may be applied to OTE but I do not consider such categorisation to demand analysis, beyond noting the work's alignment with contemporary tendencies. For example, OTE will be discussed below as a research project, and in this way fulfils De Oliviera, Oxley and Petry's observation in Installation Art in the New Millennium: The Empire of the 
Senses regarding the prevalence of the term "project" for work that focuses on process and collaboration, where outcomes can be open-ended. ${ }^{8}$ Further, the authors note the frequency of exchanges with other disciplines, such as science and technology, leading to experimental strategies beyond the visual, including negotiated interactivity; ${ }^{9}$ these tendencies are apparent in $O T E$.

The performance/installation nexus is the subject (and title) of Blair French's chapter in Amelia Jones and Adrian Heathfield's Perform, Repeat, Record: Live Art in History, in which French is particularly interested in the role of documentation. ${ }^{10}$ French's interpretation, that installation is a performative practice due to its ephemerality - "installation art is conditioned in part by an accumulation of erasures, of fading memory traces, of photographic documentation, and of sedimentary layerings of now absent presences over the architectural lining of those spaces" - is one I will take issue with below, though his attention to layerings without the melancholy tone - "production residues" - accords with my experiences. ${ }^{11}$ De Oliviera, Oxley and Petry note that documentation via photography has become a major means of viewing installation work, more common than seeing work in situ. ${ }^{12}$ They, too, maintain a melancholy tone when stating that installation documentation offers a view without experience, but also cite Brian O'Doherty who argues that photography introduces greater ambiguity, presumably expanding experience. ${ }^{13}$ De Oliviera, Oxley and Petry show that the prevalence of documentation in turn leads to changes in display, where some artists and institutions extend the installation through dialogue and interpretation. ${ }^{14}$ Regardless of one's attitude to the relationship between work and documentation, the mutually implicating relation between them is apparent.

\section{PART 2: THE RESEARCH PROJECT}

OTE is a research project as well as a work, an artistic exercise in data retention, in that it is motivated by enquiry and yields data that demand interpretation to understand their meanings. Some of these data are readily apparent, such as the demographic information and viewing behaviour of consenting participants, and photographs that document the installation space and its elements, including the performer within that space. The performer, Rachelle Rechichi, is also a research assistant within the project, and so her observations regarding participant behaviour, captured as notes within a performance journal, are another form of data. ${ }^{15}$ Others are less accessible, such as the eye-tracking videos that record the viewing behaviour of 
participants. Anonymity is guaranteed as a condition of consent and so the videos are captured as de-identified digital video files. However, an accidental discovery was made in the course of the project when it was noted that the eye-tracking videos could potentially identify participants, as their reflections can be momentarily glimpsed when the video they are watching, Telephone, depicts dark (and therefore reflective) surfaces.

There are two implications to this discovery. The first is that the accidentally recorded reflections immediately render the eye-tracking videos more visually interesting and meaningful in the context of a work about data capture; the second is that the eye-tracking videos cannot be shared as this could potentially breach anonymity. So, whilst some of the meanings and values of the research project can be enriched through viewing the eye-tracking videos as aesthetic documents, consent does not extend to sharing the digital video files capturing participant viewing behaviour, only their interpretations, noted below. Of more interest for me as a scholartist, however, is an examination of the work's unanticipated findings that are revealed through framing the work as performance research. The discovery signalled the point in the project at which the artist entered the work as a performer in the reenactment video. The methodological and ethical implications of this aspect of the project will be addressed below.

\section{Performance Research Methodology}

By framing $O T E$ as performance research, space can be made for findings that emerge from the process, rather than limiting findings to those anticipated through research design. The paradigm of performance and other arts research methodologies recognises that knowledge is "often unstable, ambiguous and multidimensional." 16 Smith and Dean's practice-as-research model, the iterative cyclic web (a name that illustrates the varieties of relationships and processes involved), notes that processdriven creative practice and research can be "directed towards emergence, that is the generation of ideas which were unforeseen at the beginning of the project." 17

In the case of $O T E$, to meet the requirements of one of the funding bodies, Edith Cowan University's eResearch Technology Funding Scheme, as well as the University's Human Research Ethics Committee (HREC), I ensured my applications made some clear claims about the data to be gathered. Namely, when viewing a video 
and wearing eye-tracking glasses, who do the participants focus on? Where do they look? How long is their attention span? These data were duly gathered and interpretations made, indicating that key focus areas are on the eyes, nose and mouth of the faces depicted in the video Telephone. This offers nothing new to the store of knowledge regarding viewing behaviour that has not already been noted by behavioural psychologists, which is unsurprising in the context of an arts-based research enquiry in which the use of eye-tracking technology was exploratory.

The most interesting parts of OTE emerged rather than being explicitly anticipated as data to be collected. In line with a process-driven research inquiry, and indeed a "project"-oriented live-art installation, I redeployed the eye-tracking device as a head-mounted camera to reenact the visitor's experience using myself as subject. To abide by the requirements of the HREC, I recreated the eye-tracking videos I wished to interpret and share by playing the role of participant within my own work. This created new audio-visual documents that extend the work's artistic outcomes and permit the documents to be interpreted as data within the research project. They can be aesthetically analyzed as images that form part of the work, and analyzed as data that provide additional evidence for behavioural findings made within other methodological domains. The unfolding of the project led to new data being collected and analyzed, leading to novel insights.

\section{Performance Research and Ethics}

OTE can be described as delegated performance, as Rachelle Rechichi attended the gallery in my stead, playing the role of a laboratory technician and collecting data. Rechichi is a writer and performer who received training in the use of Tobii Pro Glasses 2. Together we developed a character, Svetlana, who engaged with the viewers of the work. Svetlana's character was developed as a playful take on an oppressive state presence, inspired by images of Soviet-era scientists: serious, glasseswearing, and/or heavily made up. She wears a white lab coat and allows visitors to see her donning surgical gloves. Here, the Soviet era represents institutional control, with individual liberty compromised at the cost of collective security; there is an echo of this in the Data Retention Act. As a character, Svetlana developed stark contrasts between verbal directives that offered information and clear choices, with body language and tone that implied invasions of privacy, such as standing close to the side 
of the visitor without touching them and using the visitor's name more often than is customary.

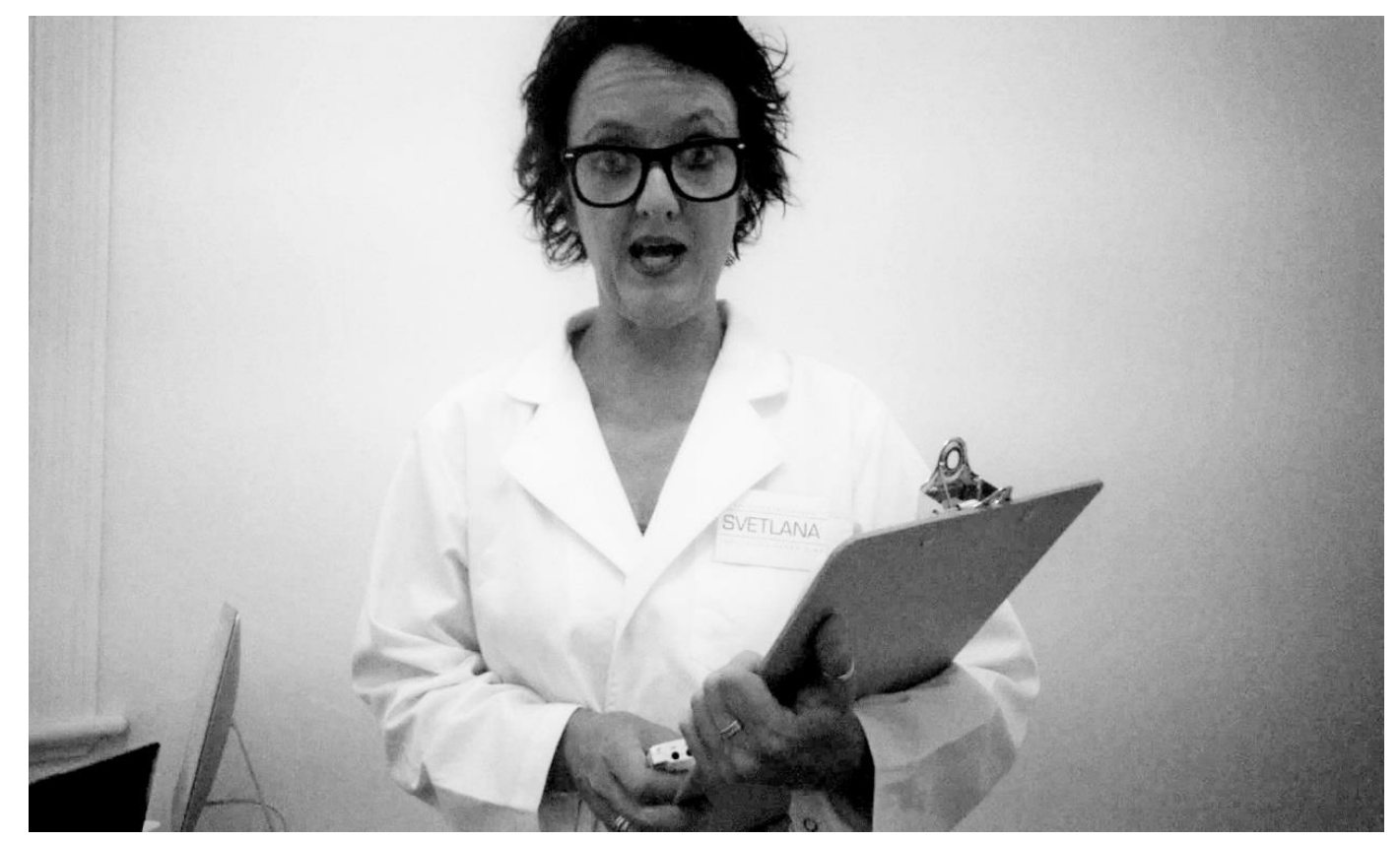

Rachelle Rechichi as Svetlana in Only the Envelope. Reenactment video still by Vahri McKenzie.

The dual roles of scholar and artist require careful negotiation of institutional processes, such as those undertaken by the HREC. OTE is performance research; its aesthetic intentions also require the participation of others and so it is "human research." As is to be expected, Edith Cowan University requires strict monitoring of ethical research behaviour. At the same time, I was concerned to not undermine the aesthetic qualities of the work via the usually bureaucratic process of gaining informed consent. Thus, a carefully prepared script addressing the requirements of the University's HREC was written, and its performance was delivered in character by Svetlana. Meeting the requirements the HREC became a significant part of the experience of $O T E$ for each participant, whether they were aware of it or not.

Although the framework of the enquiry defined a "participant" as one who consented to wearing eye-tracking glasses while watching a video and specified what could be measured as a result of participation, as the project progressed the value of "non-participants" became evident. Consent was collected from 65 participants; however, almost as many can be said to have participated without consent, by either declining to participate when approached or participating as a companion of the one who gave consent, and observing the whole process, including viewing the video, if 
they chose. As the project unfolded it became clear that interesting observations could be made about these viewers, expanding my understanding of "participants" and "participation," so Svetlana began annotating their participation and gathered notes on a number of these companion-observers. But I cannot report further on these findings in detail, including noting the exact number of these non-consenting participants, as the requirements of the University's HREC prohibit it. General tendencies and a close analysis of the meanings in terms of social behaviour, particularly in relation to "participation" and "consent" in performances of science, are addressed elsewhere. ${ }^{18}$

The reenacted participant videos are aesthetically rich and meaningful as data. They depict a visitor being greeted by Svetlana and invited to "participate;" the visitor listens to the consent script and agrees, then watches the video. Occasionally the visitor looks at Svetlana who is looking at her, and the reenactment videos capture this too. And yet, these images create challenges for the scholartist. Are they really part of the work or merely photographs of the work that was? Do the photographs authentically capture and provide sufficient evidence for the work, or do they point to the lack of access to the work and artist? If the documents are (part of) the work, can that work be performance? And, if the documents are the work, do they contribute something new? The following sections attempt to tease apart these questions in the light of some key texts in performance studies and posit responses that are relevant to OTE.

\section{PART 3: REENACTMENT DOCUMENTATION}

Contemporary art with a performative element has long been troubled by the sense that performances "disappear" as soon as they are performed. There are two issues here, where the first is practical. How is one to engage with the work beyond the moment of its live appearance for the purposes of critique, appreciation, and research? Thus, there has been a long-standing relationship with the documentation and archiving of the live art event through photography and other texts. The second issue is a philosophical one. Some take the position, most famously expressed by Peggy Phelan, that performance is only that which disappears: "Performance's being ... becomes itself through disappearance." ${ }^{19}$ Phelan's position is an argument for the supposed ontological distinctness of live performance, one that defines performance via its separateness from reproduction. In this view, my reenacted videos are not OTE; the thing that was $O T E$ ceased to exist when the live art installation was archived. The 
documentation offers evidence for the fact that the live artwork occurred but cannot hope to illuminate the experience of that performance: "The document of a performance then is only a spur to memory, an encouragement of memory to become present." 20

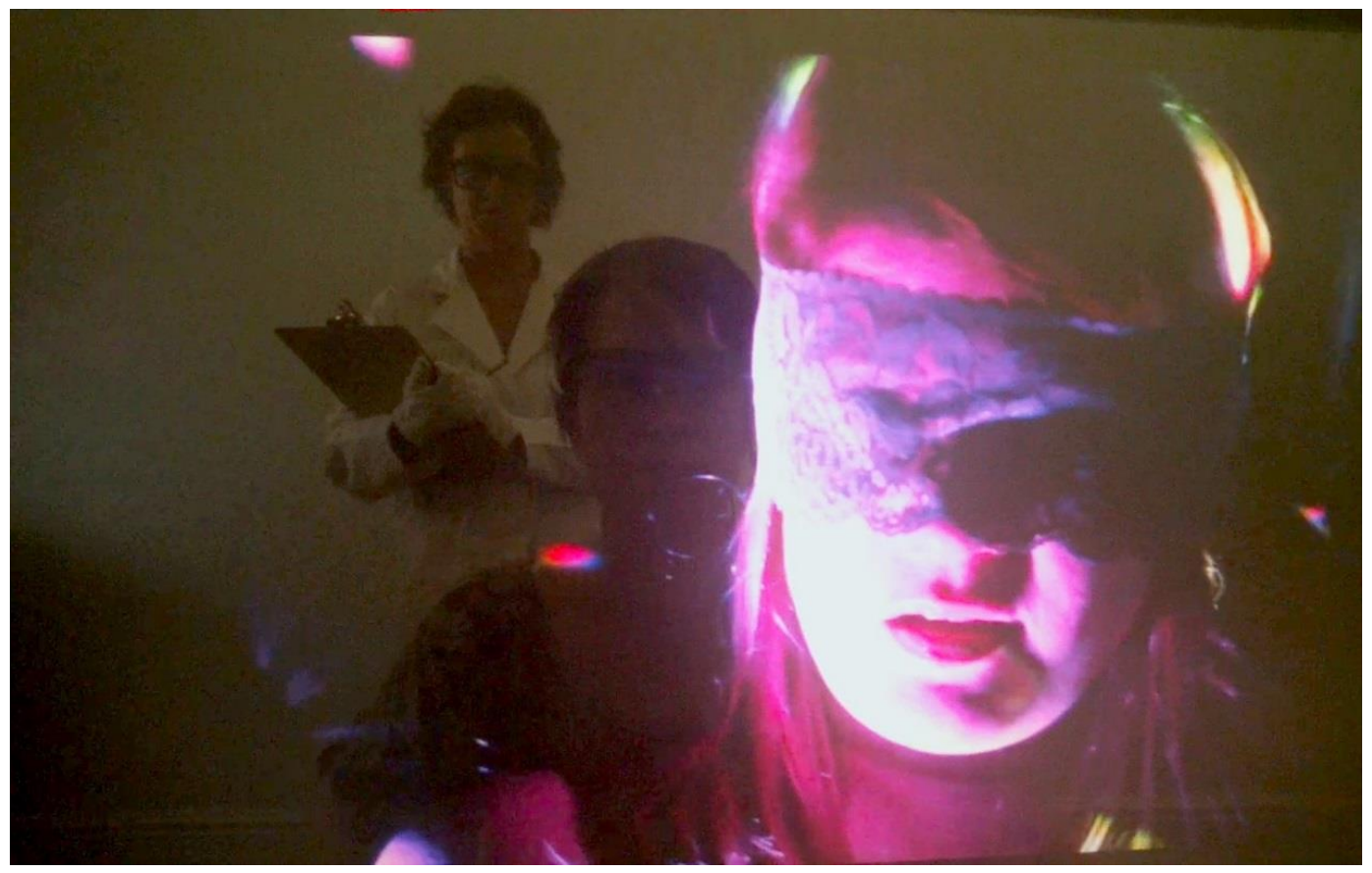

Depicted here (L to R) Rachelle Rechichi as Svetlana, Vahri McKenzie as "participant" and Gemma Ben-Ary in Telephone (see note 4), Only the Envelope. Reenactment video still by Vahri McKenzie.

\section{Performativity and Documentation}

Philip Auslander offers a critique of the argument from ontology via a focus on the uses and values of live art documentation, where performance documentation falls into two distinct modes that he calls the "documentary" and the "theatrical." The "documentary" category "represents the traditional way in which the relationship between performance art and its documentation is conceived," assuming that "the documentation of the performance event provides both a record of it through which it can be reconstructed ... and evidence that it actually occurred." ${ }^{21}$ This aligns with Phelan's position, in which the performance event precedes and authorises its documentation. The second of Auslander's categories of performance documentation is the "theatrical," encompassing those performances where the document is the only space in which the performance occurs. Cindy Sherman's Untitled Film Stills series (1977-80) is exemplary of this category, "cases in which performances were staged 
solely to be photographed or filmed and had no meaningful prior existence as autonomous events presented to audiences." 22

Within the traditional ontology of performance, the "documentary" and "theatrical" categories are considered mutually exclusive. If one insists on the ontological relationship between performance and its documentation, those documents in the theatrical category had no existence prior to their documentation and so are not "performances" at all. ${ }^{23}$ However, Auslander's argument shows that the two documentary modes have much in common, in that the images in both categories were staged for the camera; even when a live audience was present, “... the events were staged to be documented at least as much as to be seen by an audience." ${ }^{24}$ Auslander illustrates with the example of Vito Acconci's Blinks (1969), which undermines the apparent distinction further. In this work the artist takes photographs while walking down a street according to a set pattern; the work's documentation includes the simple instructions for the piece and the resulting photographs. On the one hand this provides evidence of the work in a documentary and ontological manner; on the other hand there was no audience for the performance event and it is only through Acconci's documentation that the performance exists. Yet, the documentation does not depict the artist; rather, it shares the meanings of the performance; it performs the performance. This exemplifies Auslander's notion of "the performativity of documentation itself."

... the act of documenting an event as a performance is what constitutes it as such. Documentation does not simply generate image/statements that describe an autonomous performance and state that occurred: it produces an event as a performance. $^{25}$

I can usefully apply Auslander's discussion to $O T E$ and illustrate the blurry line between "documentary" and "theatrical" performance documentation. Records such as installation-view photographs are "documentary" inasmuch as they provide evidence that the performance occurred and could be used to recreate it; they capture the performer in the space, although that performer is not the artist. Photographs of Svetlana such as the work's publicity image are "theatrical" and are framed as performances in themselves. The reenacted videos are both; by documenting the visitor experience that was observed, staged and reenacted in a reflexively "theatrical" sense, they provide the best evidence for re-creating the work, as well as an authentic sense of the performance as experienced by those visitors. The reenacted videos, 
made within the time and space of the live art installation, are as much Only the Envelope as the visitor experience, though qualitatively different.

Moreover, framing performance through the performative act of documentation reveals "authenticity" as an effect only, not a reality, allowing Auslander to conclude that:

... the authenticity of the performance document resides in its relationship to its beholder rather than to an ostensibly originary event: perhaps its authority is phenomenological rather than ontological ... It may well be that our sense of the presence, power, and authenticity of these pieces derives not from treating the document as an indexical access point to a past event but from perceiving the document itself as a performance that directly reflects an artist's aesthetic project or sensibility and for which we are the present audience. $^{26}$

The performativity of documentation shifts defining performance ontologically to performance by artist's fiat, or by function; yet, Auslander's argument requires the imposition of a disciplinary boundary. Whilst works in the "theatrical" category become available to an audience solely through their documentation and those in the "documentary" category have a dual existence, the difference for Auslander is not substantial because the tradition of performance art documentation is to make the artist's work available to a larger audience, and both forms of documentation do so. He separates this function of documentation from the ethnographic tradition of performance art history which focuses on the specific interactions between performer and audiences: "performance art documentation participates in the fine art tradition of the reproduction of works rather than the ethnographic tradition of capturing events. ${ }^{27}$ This supposed disciplinary distinction regulating the relative importance of work and event is inadequate, and will be returned to.

\section{Authenticity and Documentation}

In Phelan's construction of performance, the process of documentation mediates what would otherwise be direct access to the live artwork, guaranteeing the artist's "presence" without "reproduction."

Performance implicates the real through the presence of living bodies ... Without a copy, live performance plunges into visibility - in a maniacally 
charged present - and disappears into memory, into the realm of invisibility and the unconscious where it eludes regulation and control. ${ }^{28}$

This passage reveals Phelan's political impetus such that denying reproduction is seen as a way of escaping commodification, but it also privileges "visibility" at the expense of other modes of experience. It may be that the passage of time between Phelan's seminal Unmarked and now has shown that increasingly sophisticated modes of reproduction complicate any simple relation between the "live" and the "record", such that many "live" works include aspects of digital reproduction (OTE included). But the supposed link between live artworks and authentic access to "the real" is problematic for other reasons.

Amelia Jones' position “specifically rejects such metaphysical conceptions of body art or performance as delivering in an unmediated fashion the body of the artist to the viewer." 29 Jones's analysis debunks the myth of "presence" because meaning is made between subjects. The body in live art is "contextualised within the codes of identity" and relies on "a receptive context in which the interpreter or viewer may interact with it." 30 For Jones, live performance should be understood phenomenologically, where that phenomenology is intersubjective; she replaces the ontological priority of the live performance with mutual supplementarity between the event and its documents. There is no "real" or "authentic" access to meaning offered via live performance; it follows from this that nothing is lost through its documentation. If live performance makes pronounced the "intersubjectivity of the interpretive exchange," documents are "just as easily, if not as obviously, contingent in that the meaning that accrues to the image of the body is open-ended and dependent on the ways in which the image is contextualized and interpreted." ${ }^{\prime 1}$ Far from any ontological distinctness of live performance, any separateness from reproduction, the performer's body does not guarantee presence because it itself is "incomplete" without its interpretation by another body-subject.

Meanings are made between performer and viewer at the level of the live as well as at the level of the record. In OTE, this is further complicated by the different kinds of viewer/participant experience described above, as well as the delegation of the live aspect of the performance from the artist to a hired performer/research assistant. According to Claire Bishop, delegated performance is "the act of hiring nonprofessionals or specialists in other fields to undertake the job of being present 
and performing at a particular time and at a particular place on behalf of the artist, and following his or her instructions." ${ }^{32}$ In keeping with the commodification of culture, Bishop observes that the delegated performance tendency coincides with managerial changes in the economy such as outsourcing, ${ }^{33}$ so that, "Presence today is arguably less a matter of anti-spectacular immediacy (as was the case during the 1960s) than evidence of precarious labor." 34

Furthermore, none of the documentation of $O T E$ explicitly features "the artist" except through reflection in the reenacted videos. ${ }^{35}$ Nor do the reenacted videos provide evidence of an audience that "authenticates" the "original" live artwork. Rather, the reenacted videos respond to meanings that evolved during the live art installation work and attempt to share what visitors saw; they reflexively cultivate a reality effect through the use of a head-mounted camera (the eye-tracking device) in keeping with the work's ironic and playfully recursive tone. As the work progressed, what struck me was the aesthetic qualities of the participant eye-tracking videos, which reflect the immediacy, authenticity and intimacy of first-person videos made using a head-mounted camera like a GoPro, an effect of contemporary developments in documentary media that relate to first-person accounts of risky and/or eyewitnessed events. "Authenticity" is a term to be tested and toyed with, in keeping with the questionable "authenticity" of our digital identities that are endlessly generated and recycled in the online world.

$O T E$ is incomplete without these videos because they substantially reflect my aesthetic project. By reenacting the viewer's experience I am able to show the effect of unintentionally revealing the viewer by capturing patterns of reflections in Telephone's dark surfaces. Further, they contribute something new to the store of knowledge that the other "documentary" records do not. Whilst a GoPro only shows the general direction of a wearer's head and the data-rich eye-tracking systems show what the wearer is actually attending to, in the performance research of OTE the eyetracking data gathered are unremarkable; it is the reenacted videos that extend the work's artistic outcomes by illustrating the recursive nature of data capture by reflecting back the gazer's gaze. As an unanticipated outcome of the live art installation, my reenacted videos do not simply reproduce the staged encounter that dramatizes looking and being looked at, but perform it again. 


\section{(Un)tangling Liveness and Documentation}

At least since the age of mechanically reproduced images, viewers experience a strong sense of conflation between photographic records with their original subjects, as has been well documented in the literature of the semiotics of photography. ${ }^{36}$ Powerful indexical and iconic relationships encourage us to consider the photographic signifier to exactly correspond with the signified source, such that viewers willingly substitute its representation for the real world itself. Ironically, this sense develops alongside technological developments so that photographic qualities (for example, distorted tempi in early film, today's high resolution digital video) become linked with the periods in which they were developed and we accommodate aesthetic differences in our understanding of the past or present "real world" depicted. This applies to the present discussion of performance documentation because the photographic qualities, "grainy black and whites or flickering film stock" that captured much pioneering performance art of the 1960s and 1970s, Rebecca Schneider writes, "could posit the event as having priority over its documentation." 37 However, as I hope the discussion to this point has shown, it is more useful to consider live performance and photographic documentation in a mutuallysupplementary relationship: "The body art event needs the photograph to confirm its having happened; the photograph needs the body art event as an ontological 'anchor' of its indexicality." 38 More useful, and yet, Jones' powerful argument maintains a binary construction of the relation between the live and the record, as if there were only two moments involved. Quoting Phelan, Schneider rhetorically asks:

Is the live really only a matter of temporal immediacy happening only in an uncomplicated now, a "transitory" present, an im-mediate moment? Is a "maniacally charged present" not punctuated by, syncopated with, indeed charged by other moments, other times? ${ }^{39}$

Earlier I noted that Auslander pushes away from an ontology of the live in his discussion of performance documentation by introducing a disciplinary distinction between the fine art and ethnographic traditions of documenting "works" versus "events," a distinction that, as a scholartist, I find artificial and not very useful. ${ }^{40} \mathrm{I}$ maintain that OTE is "performance," which does not limit contexts that relate to the traditions of visual arts such as installation. Additionally, in light of the collaborative, participatory and socially engaged agenda that is inextricable from its aesthetic 
concerns, OTE can be described as applied performance, where such performances are to be found across a variety of practices. ${ }^{41}$ It could be that we are witnessing a new "turn" in performance studies that accounts for changing experiences of the world understood through temporality, embodiment and engagement with others. In her introduction to Perform, Repeat, Record: Live Art in History, Amelia Jones notes that:

The performative, loosely understood ... as the reiterative enactment across time of meaning (including that of the "self" or subject) through embodied gestures, language, and/or other modes of signification, opens up the supposedly static work of art constructed by art history to the temporal, and to the vicissitudes of invested and embodied engagement by visitors to, participants in, or viewers of the work. ${ }^{42}$

Perhaps the disciplinary distinction is one Auslander will reconsider; in the article "Digital Liveness" he attempts to outline a phenomenological perspective on liveness (rather than critiquing the ontology of liveness, which was the primary aim of his book Liveness ${ }^{43}$ ) and concludes that the benefit of a phenomenological perspective is the focus on "a specific relation between self and other, a particular way of 'being involved with something, $", 44$ which I take to apply to performers, viewers, and work alike. I do not think disciplinary distinctions are required; indeed, Auslander himself lays a clue when, in a note accompanying the distinction between "works" and "events," he writes:

To speak of recreating a performance suggests the reconstruction of an object. By contrast, the term revival used in English to describe theatrical productions of existing plays suggests the reawakening of an organic entity rather than the rebuilding of a lost object. ${ }^{45}$

What about reenactment? There is a "pointedly temporal aspect to the term," says Schneider, that "troubles linear temporality by offering at least the suggestion of recurrence," where such troubling courts "the ancient (and tired) Western anxiety over ideality and originality." 46 In Performing Remains: Art and War in Times of Theatrical Reenactment, Schneider offers a way through the debate that I have here traced some elements of, motivated by reenactment art that "poses a certain challenge to our long-standing thrall, fuelled by art-historical analyses of performance, to the notion that live performance disappears by insisting that, to the contrary, the live is a vehicle for recurrence." 47 Schneider addresses and, ultimately, rejects both Phelan's position - that the live is that which cannot be recorded - and Auslander's as 
expressed in Liveness - the live is that which can be recorded, because "both Phelan and Auslander position the body performing live as not already a matter of record." $" 48$

Schneider turns our attention towards the ongoing nature of the activities of performing and recording across time. "The delegation of live performance as vanishing in time and photography as capturing time has contributed to our inability to read the two media as intimately related, even co-constituted, in the gesture of the still." 49 Schneider's path through the faulty binary between "live" and "recorded" is guided by the ways in which live performance contains echoes of the past archived in collective memory and embodiment - "striking a pose partakes of reenactment, and reenactment defers its site in multiple directions, ${ }^{, 50}$ - as well as the ways in which archived records are not static but active mechanisms that perform the act of saving: "another kind of performance ... part of an embodied repertoire - a set of live practices of access." ${ }^{51}$ She offers historical precedents, tableaux vivants, and the tradition of the "still" in theatrical reenactment, that illustrate the complicity of performance and the still image. Performance and live arts have as much to do with remaining, via "reenactment, recurrence, and repetition," as with disappearance. ${ }^{52}$

The point is well-made by returning to the previous example of Cindy Sherman's photographs that, in Auslander's analysis, are theatrical documents. Reading one medium through another, Schneider complicates this further by drawing our attention to moments either side of the received photograph. Sherman's photographs are a record, a document, and the site of the performance, but they are also a record/performance that reenacts past records/performances.

... the performance takes place as photograph, and in this sense, might be considered re-documentation as much as reenactment, troubling a distinction between the two. This is to say that the photographs themselves (not just the actress/photographer) reenact film stills, reenact oil painting, and mimic other media. $^{53}$

In this way, Schneider shows how photographs, long associated with stillness and death, also address the future and the possibility of rediscovery.

Numerous examples and formidable scholarship aside, Schneider's argument accords most clearly with my experience and reflection as a scholartist when I consider OTE, its layers, and recursions. The work was "performed" repeatedly, for audiences of one or two, in an art gallery setting. OTE was also "performed" with eye-tracking-glasses-acting-as-camera in an explicit relationship with documentation; 
this is a kind of "reenactment art" in that I reenacted the visitor experience within the installation whilst those experiences were still unfolding. The "experience" of the reenactment video includes, then, Svetlana's self-conscious performance via the artist's reproduction of the visitor's experience, in addition to viewing Telephone via the head-mounted eye-tracking camera. The reenactment video mixes theatricality and documentality, performing "the inter(in)animate tangle between liveness and documentation." $" 54$

Documents are ubiquitous in the digital age, and in many forms of contemporary art, such as installation art, documentation is the norm; OTE is part of this contemporary art tradition. It was built on an existing document (the video Telephone) and it aimed to generate further documents as part of the ordinary mechanics of a twenty-first century art-maker who is obliged to explain and offer evidence for their work and its claims. OTE generated data that offer information about where we look, who we look at and how long we look at a particular work of art using eye-tracking technologies. Further, the live art installation staged encounters that dramatize the act of looking, generating narratives that offer another way of investigating the act of sharing personal data. This qualitative data is in the form of reflections from a performer to whom I delegated this performance, as well as videos reenacted within the work. New artworks were generated within the time and space of the installation; these artworks both extend the creative outcomes of OTE, and figure as data in themselves. The documents additionally reflect participatory social contexts, as well as mediatized performance contexts, in which authenticity and presence are negotiated.

But OTE is also about documents and so I question their value and meanings. The documents of OTE extend the work by capturing some of its values, but they require interpretation to be meaningful. These considerations have implications for the framing of the project as research, where documentation becomes "data." If, for example, the "audience" of the work is not just those participants who formally consented but also those who engage with any of the documents, within the installation or afterwards, the data set becomes unbounded. Institutional structures such as Edith Cowan University's Human Research Ethics Committee provide arbitrary boundaries but abiding by them diminishes meaning. Moreover, I intentionally deploy various ways of complicating data, so that simultaneously I posit the document as a form of data driving the artwork, and interrogate the way this data 
may be used. I would like to suggest that the video reenactments revealed themselves with something like an agency of their own, and yet, any writing up is contingent and provisional. Indeed, "when we habitually read documents as evidence and evidence as indication of a past supposedly gone by, do we overlook the liveness of temporal deferral, the real time of our complicities?" 55 For now, there is an equivalence between all aspects of the work, where all is open to interpretation and none is objective.

${ }^{1}$ This full title was used for institutional funding and human research applications in which the work was considered "research;" while the shorter title was used in the gallery space in which the work was considered "art".

${ }^{2}$ Rebecca Schneider, Performing Remains: Art and War in Times of Theatrical Reenactment (London and New York: Routledge, 2011), 29.

${ }^{3}$ Vahri McKenzie, Only the Envelope, 2016, live art installation, Bunbury, Western Australia: Archive Room, Bunbury Regional Art Galleries.

${ }^{4}$ Recursion and reflexivity predate this current project; the film which became the basis for the live art installation is itself characterised by recursion and reflexivity: Vahri McKenzie, Gemma Ben-Ary, Jacob Lehrer, and Alex McKee, Telephone, 2014, digital video, Perth, Western Australia: Spectrum Project Space. Available to download from http://ro.ecu.edu.au/ecubooks/1/

${ }^{5}$ Vahri McKenzie, "Only the Envelope: Opening up Participation, Surveillance and Consent in Performance," Performance Matters 3, no. 2 (forthcoming 2017).

6 "Interview with Michael Brissenden, ABC AM," Australian Government Department of the Prime Minister and Cabinet, August 6, 2014, http://pmtranscripts.pmc.gov.au/release/transcript-23710

${ }^{7}$ Cited in Emma Griffiths, "Data Retention Laws: Tony Abbott says Government 'Seeking Metadata', Not Targeting People's Browsing History," ABC News (August 7, 2014).

${ }^{8}$ Nicolas De Oliveira, Nicola Oxley and Michael Petry, Installation Art in the New Millennium: The Empire of the Senses (London, UK: Thames and Hudson 2003), 81 .

${ }^{9}$ Ibid., 5 .

${ }^{10}$ Blair French, "Aftermath: The Performance/Installation Nexus," in Perform, Repeat, Record: Live Art in History, ed. Amelia Jones and Adrian Heathfield (Bristol, UK; Chicago, Illinois: Intellect, 2012), 413-424.

${ }^{11}$ Ibid., 414.

${ }^{12}$ De Oliveira et al., Installation Art in the New Millennium, 79.

${ }^{13}$ Ibid., 80.

${ }^{14}$ Ibid., 80. 
${ }^{15}$ Observations pertaining to companion-observers who accompanied consenting participants are another form of inaccessible data that cannot be fully reported within the context of the research enquiry. See note 5.

${ }^{16}$ Hazel Smith and Roger T. Dean, "Introduction: Practice-led Research, Research-led Practice - Towards the Iterative Cyclic Web," in Practice-led research, research-led practice in the creative arts, ed. Hazel Smith and Roger T. Dean (Edinburgh, UK: Edinburgh University Press, 2009), 3.

${ }^{17}$ Ibid., 23.

18 The key finding is that different behaviours are observed between those watching the performance as companion-observer and those taking part in the performance as "participant," suggesting that consenting to participation leads to a compliance not seen when not formally consenting despite both roles being played out within the same small space. See note 5 .

${ }^{19}$ Peggy Phelan, Unmarked: The politics of performance (London, New York: Routledge, 1993), 146.

${ }^{20}$ Ibid., 146.

${ }^{21}$ Philip Auslander, "The Performativity of Performance Documentation," in Perform, Repeat, Record: Live Art in History, ed. Amelia Jones and Adrian Heathfield (Bristol, UK; Chicago, Illinois: Intellect, 2012), 47. This influential paper was first published in PAJ: A Journal of Performance and Art 28, No. 3 (2006), 1-10.

${ }^{22}$ Ibid., 49.

${ }^{23}$ Ibid., 49.

${ }^{24}$ Ibid., 51.

${ }^{25}$ Ibid., 53, both quotes here are from this page; emphasis in original.

${ }^{26}$ Ibid., 57, emphasis in original.

${ }^{27}$ Ibid., 54-5, emphasis in original.

${ }^{28}$ Phelan, Unmarked, 148.

${ }^{29}$ Amelia Jones, Body Art/Performing the Subject (Minneapolis: University of Minnesota Press, 1998), 33.

${ }^{30}$ Ibid., 34.

${ }^{31}$ Ibid., 34.

${ }^{32}$ Claire Bishop, "Delegated Performance: Outsourcing Authenticity," October 140 (2012), 91.

${ }^{33}$ Ibid., 103-4.

${ }^{34}$ Ibid., 105.

${ }^{35}$ Documentation may also incidentally depict the artist as an unidentified subject in the digital video Telephone in an example of the recursion and reflexivity noted (4) above. 
${ }^{36}$ For example, see Roland Barthes, "The Photographic Message," in Image, Music, Text, ed. and trans. Stephen Heath (London, UK: Fontana Press, 1977), 15-31.

${ }^{37}$ Schneider, Performing Remains, 28.

${ }^{38}$ Jones, Body Art, 37.

${ }^{39}$ Ibid., 92.

${ }^{40}$ See note 27.

${ }^{41}$ Nicola Shaughnessy includes devising, performance art, durational, site/place responsive, intermedial and live art in these practices; Nicola Shaughnessy, Applying performance: Live Art, Socially Engaged Theatre and Affective Practice (Houndmills, Basingstoke, Hampshire; New York: Palgrave Macmillan, 2012), xv.

42 Amelia Jones, "The Now and the Has Been: Paradoxes of Live Art in History," in Perform, Repeat, Record: Live Art in History, ed. Amelia Jones and Adrian Heathfield (Bristol, UK; Chicago, IL: Intellect, 2012), 12.

${ }^{43}$ Philip Auslander, Liveness: Performance in a Mediatized Culture, (London; New York: Routledge, 1999).

${ }^{44}$ Philip Auslander, "Digital Liveness: A Historico-Philosophical Perspective," PAJ: A Journal of Performance and Art 34, No. 3 (2012), 10, emphasis in original.

${ }^{45}$ Note 18, Auslander, "The Performativity of Performance Documentation," 58, emphasis in original.

${ }^{46}$ Schneider, Performing Remains, 30.

${ }^{47}$ Ibid., 29.

${ }^{48}$ Ibid., 92, emphasis in original.

${ }^{49}$ Ibid., 148.

${ }^{50}$ Ibid., 161.

${ }^{51}$ Ibid., 108, emphasis in original.

${ }^{52}$ Ibid., 144.

${ }^{53}$ Ibid., 154, emphasis in original.

${ }^{54}$ Ibid., 29.

${ }^{55}$ Ibid., 142. 